\title{
Infiltrating Bladder Urothelial Carcinoma, Sarcomatoid Variant with Heterologous Elements
}

National Cancer Institute

\section{Source}

National Cancer Institute. Infiltrating Bladder Urothelial Carcinoma, Sarcomatoid Variant with Heterologous Elements. NCI Thesaurus. Code C39825.

A variant of infiltrating bladder urothelial carcinoma. It is characterized by sarcomatoid features with heterologous elements. 